\title{
Geochemistry and Glacial Dispersal Patterns of Kimberlite Indicator Minerals in the South Slave Province, NT
}

\author{
D. CAMPBELl ${ }^{1}$, S. ZUREVINSKI ${ }^{2}$, B. ElliotT $^{3}$ \\ ${ }^{1}$ Lakehead University, Thunder Bay, ON, Canada, P7B 5E1; \\ decampbe@lakeheadu.ca \\ ${ }^{3}$ Northwest Terriotires Geological Survey, Yellowknife, NT, \\ Canada, X1A $1 \mathrm{~K} 3$
}

The geochemistry and distribution of garnets in the southern Slave Province could have considerable implications for drift prospecting and diamond potential. Presented here is a study interpretting geochemistry in dispersal trains of the Slave Province. Over one-hundred-thousand garnets have been sampled from the northern Slave Province with quantitative analyses conducted on each sample, and the data has been compiled for public release (NTGS Data Hub, 2018). A smaller subset of samples have been collected in the southern Slave Province by this study and the NTGS within recent years. Data from the NTGS is used in this study to construct regional maps showing dispersal trains of indicator minerals and chemistry of indicator garnets throughout the region. The variation in dispersal train pattern, size, mineralogy, and chemistry are being utilized to assess the southern Slave for it's kimberlite potential. The geochemistry of garnets is used to make further observations into the diamond potential of the area using the garnet classifications G3D, G4D, G5D, and G10D (Grutter et al., 2004). It has been observed that there is an abundance of $\mathrm{Na}_{2} \mathrm{O}$ rich $(>0.07 \mathrm{wt}$ $\%)$ garnets in the northern Slave Province and a deficit of $\mathrm{Na}_{2} \mathrm{O}(<0.07 \mathrm{wt} \%)$ in garnets of the south. There is also a visible discrepency in olivine in the north and south, with the north Slave showing olivine in dispersal trains and the south lacking any olivine. These discrepancies in $\mathrm{Na}_{2} \mathrm{O}$ could be indicative of pressure/temperature conditions that coincide with diamond formation in the north (Grutter et al., 2004). The olivine dispersal may be the product of glacial dispersal in conjunction with the facies/mineralogy of kimberlites in the immediate area.

Government of the Northwest Territories (GNWT). (2018). Northwest Territories Geological Survery Data Hub. Retrieved from https://datahub-ntgs.opendata.arcgis.com/

Grütter HS, Gurney JJ, Menzies AH, Winter F (2004) An updated classification scheme for mantle-derived garnet, for use by diamond explorers. Lithos 77(1-4):841-857 
